\title{
SEDOPTICA Newsletter
}

\section{Noticias de SEDOPTICA}

\author{
María S. Millán, Luis Plaja e Ignacio Moreno \\ Presidenta, Vicepresidente y Presidente Anterior de SEDOPTICA
}

DOI: dx.doi.org/10.7149/OPA.53.3.ii

Tras el paréntesis estival, empezamos un nuevo curso con la pandemia extendida por todo el mundo y muchas incertidumbres. Como en otras sociedades científicas, en SEDOPTICA hemos trabajado desde el principio para afrontar las dificultades, reconduciendo las actividades programadas y diseñando otras nuevas basadas en la comunicación mediante plataformas virtuales. Reconocemos la labor de los organizadores, obligados a adaptar los planes iniciales, y expresamos nuestra gratitud a todos los colaboradores y participantes por su ayuda y comprensión. Son muchas las limitaciones sobrevenidas pero, precisamente en los tiempos difíciles, la ciencia y sus aplicaciones pueden jugar un papel esencial para el beneficio común. SEDOPTICA se suma a las sociedades que amplían las vías para comunicar los avances del conocimiento. La vida sigue y la Luz es, sin duda, nuestro mejor estímulo.

\section{SEDOPTICA y sus miembros}

La Asamblea general ordinaria de SEDOPTICA se celebró en la fecha prevista del 9 de julio de 2020, pero no en el marco inicialmente programado de la Reunión Nacional de Espectroscopia por las restricciones de movilidad impuestas por la pandemia. Por primera vez, la asamblea anual de nuestra sociedad se reunió de forma totalmente virtual. En el transcurso del acto y a partir del resultado de una votación telemática previa, se proclamó a Luis Plaja Rustein (Universidad de Salamanca) como nuevo Vicepresidente de SEDOPTICA (Figura 1).

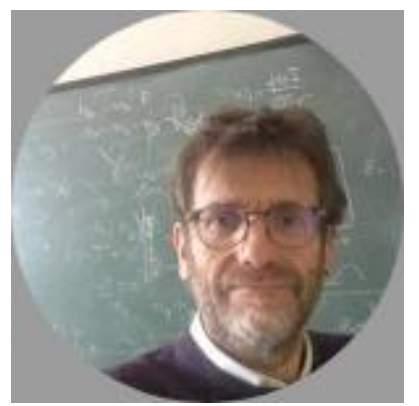

Fig. 1. Luis Plaja Rustein, Vicepresidente de SEDOPTICA (julio 2020)

El informe de secretaría señaló un total de 357 socios a fecha del 8 de julio, distribuidos por comunidades autónomas según se indica en la Figura 2. La información detallada de las actividades de los comités y áreas transversales de la sociedad durante el año 2019, incluidas las del comité editorial de la revista Optica Pura y Aplicada, están recopiladas en la Memoria anual accesible por internet. La Junta Directiva, compartiendo la opinión expresada por otros socios, animó a realizar actividades relacionadas con el Diseño Óptico y atraer a los integrantes de la comunidad española que trabajan en esta área temática, poco implantada todavía en nuestra sociedad. Se propuso el desarrollo de un grupo de trabajo en este campo ya que la creación de un comité, según la propuesta sometida a consulta telemática de los socios, previa a la asamblea, no había alcanzado el aval establecido por los estatutos. Se reconoció un nuevo reto ante los congresos y eventos de la sociedad programados para el año 2021 o aplazados en 2020. Entre ellos cabe destacar la celebración de la próxima Reunión Nacional de Óptica. Se propuso estudiar, de forma conjunta con los organizadores de los diversos eventos, el escenario de incertidumbre por la evolución de la pandemia y actuar de forma coordinada para un mejor aprovechamiento de los recursos disponibles. 


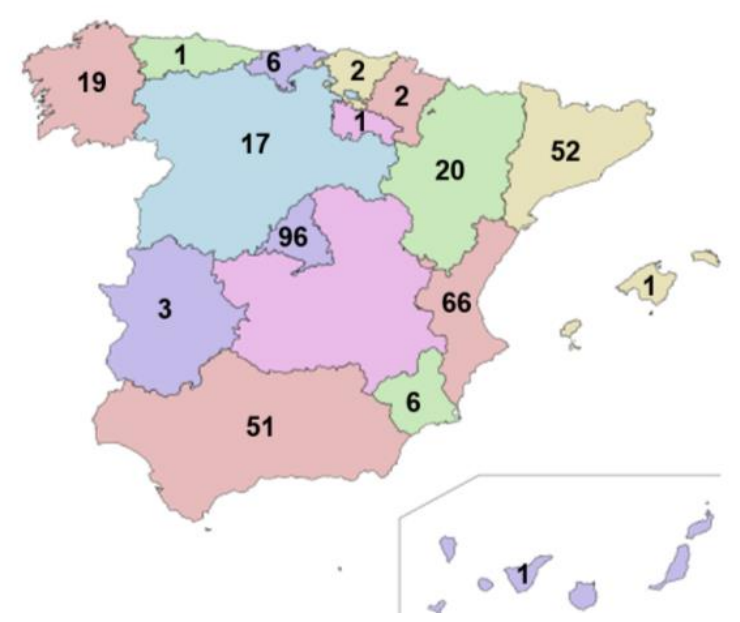

Fig. 2. Distribución de socios por comunidades autónomas (julio 2020).

María Teresa Flores (Universidad de Santiago de Compostela) ha sido elegida Secretaria de la European Optical Society (EOS), tal y como fue anunciado en la asamblea general anual de esa sociedad, celebrada el 7 de septiembre. También en la EOS, Humberto Michinel (Universidad de Vigo) ha completado su mandato como presidente y pasa a ser presidente anterior. Celebramos la continuidad de miembros de SEDOPTICA en el comité ejecutivo de la EOS y les deseamos mucho éxito en sus respectivas gestiones.

María Viñas (Instituto de Óptica, CSIC, Madrid), coordinadora del Área de Mujeres en Óptica y Fotónica y Vicepresidenta del Comité de Visión de SEDOPTICA, ha sido galardonada por EuroScience con el "Best Europe's Young Researcher Award" en la categoría de PostDoc. Además del reconocimiento por el trabajo realizado, felicitamos a la investigadora por este nuevo estímulo en su trayectoria científica.

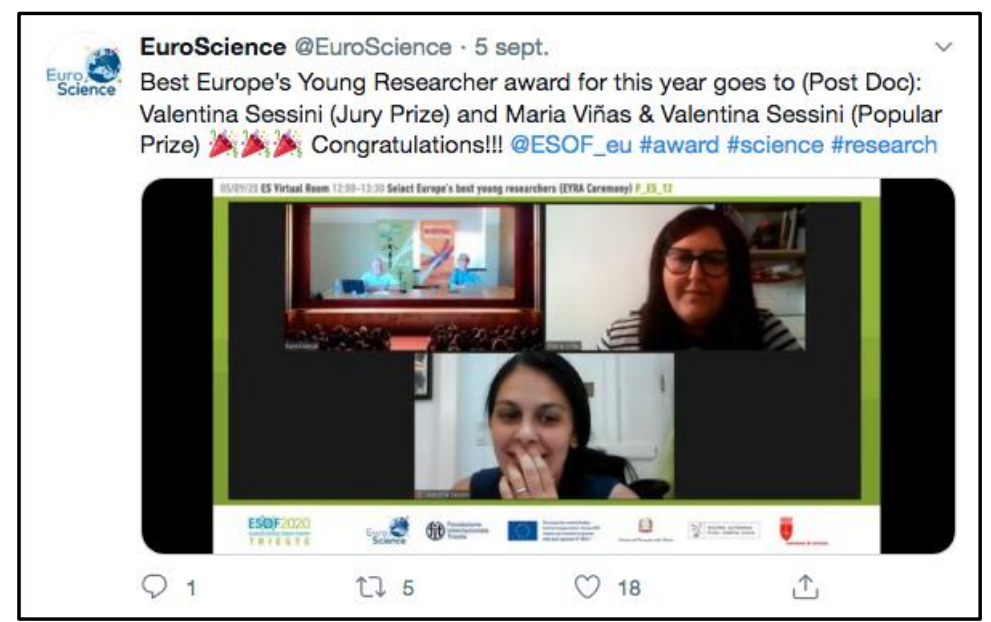

Fig. 3. María Viñas (arriba derecha de la imagen) es galardonada por EuroScience (5 septiembre 2020).

\section{Actividades y próximos eventos}

La Fundación Española para la Ciencia y la Tecnología (FECYT) notificó el 13 de julio que la revista Óptica Pura y Aplicada había superado con éxito el proceso de renovación del Sello de Calidad FECYT 2020. SEDOPTICA celebra la buena noticia y el éxito de su revista. Asimismo, felicita a todos los que la utilizan, autores y lectores, así como al comité editorial presidido por Lluís Marsal. Nuestra sociedad agradece a todos los que colaboran para que esta revista mantenga e incremente su nivel de calidad científica, desde autores y revisores individuales hasta los miembros del consejo de redacción, los editores asociados, el comité asesor científico y los asesores internacionales. 


\section{Noticias de SEDOPTICA}

El Área de Mujeres en Óptica y Fotónica, en su Programa Mentoras, ha venido desarrollando seminarios virtuales en el ciclo "Científicas Conectadas". Las charlas de finales de junio trataron el tema Manual de supervivencia para la carrera científica. El Área Joven organizó una serie de webinars sobre la Carrera Profesional en Óptica que contó con la participación de varios jóvenes que han iniciado su carrera investigadora en diversos campos de la óptica. Ambas series de seminarios virtuales ofrecen un excelente material para los que empiezan su carrera y desean conocer otras experiencias próximas relatadas en primera persona. Recordamos que todos los videos están accesibles en el canal YouTube de SEDOPTICA.

El Comité de Óptica Cuántica y No Lineal ha puesto en marcha la primera edición de los premios Ramón Corbalán de divulgación y enseñanza de los temas de su ámbito (Figura 4). Los premios rinden homenaje al profesor Ramón Corbalán, destacado miembro de nuestra sociedad y tristemente desaparecido en 2019. En la sección de información de los comités se desarrolla esta noticia con más detalle.

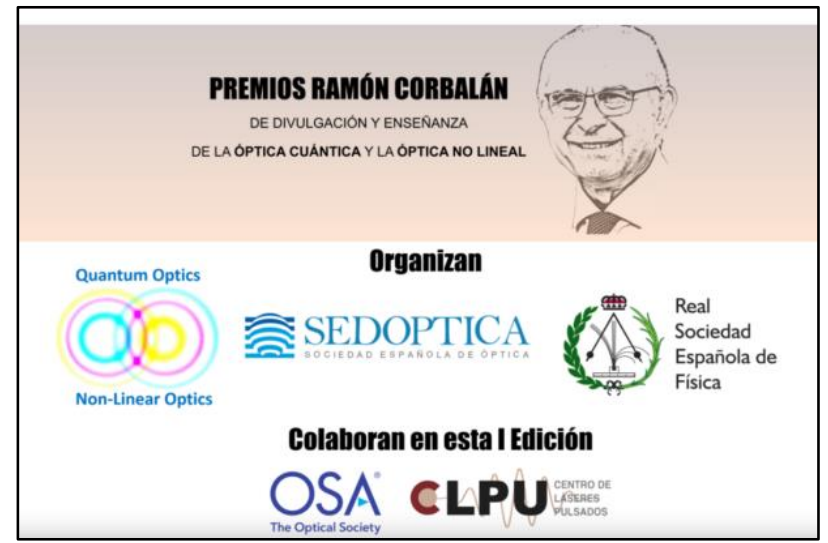

Fig. 4. Anuncio de la primera edición de los Premios Ramón Corbalán

Otros grupos continúan con la remodelación de las actividades afectadas en mayor o menor medida por las restricciones y recomendaciones sanitarias. Cabe mencionar, entre ellas, la resolución del Premio Justiniano Casas, que otorga el Comité de Técnicas de la Imagen, y el Acto Central del Día de la Luz. Precisamente sobre este último tema, la coordinadora del grupo organizador Elisabet Pérez (Universitat Politècnica de Catalunya) ofrece más información en otro apartado. Se ha celebrado en septiembre el ciclo de conferencias "La Luz: vida, ciencia, progreso" (Figura 5) organizado por las tres Academias de Ciencias de la Comunidad Autónoma de Andalucía (de Granada, Sevilla y Málaga) y el Instituto de Academias de Andalucía, a iniciativa de Enrique Hita, presidente anterior y socio de honor de SEDOPTICA. Junto con Enrique Hita, actual Presidente de la Academia de Ciencias Matemáticas, Físico-Químicas y Naturales de Granada, fue conferenciante Luis Jiménez del Barco, académico de la misma Academia de Ciencias de Granada y miembro de SEDOPTICA. Este ciclo de conferencias es un ejemplo de las actividades programadas con motivo del Día Internacional de la Luz 2020 que la situación de alarma sanitaria obligó a aplazar y que se ha llevado a cabo, felizmente, de manera telemática.

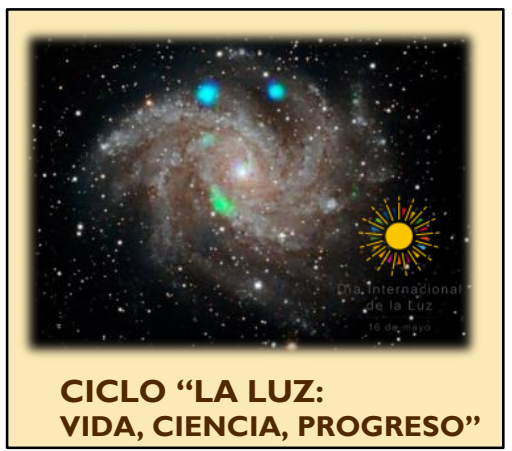

Fig. 5. Ciclo de conferencias transmitidas desde Andalucía los días 16 y 17 de septiembre de 2020. 


\section{Noticias de SEDOPTICA}

La Confederación de Sociedades Científicas de España (COSCE) está organizando para el próximo otoño la Jornada de Sociedades en formato virtual. Este año estará dedicada al Planeta. El tema elegido incluye una variedad de aspectos relacionados con la Luz y sus aplicaciones. En la llamada a participar (Salomé Prat, CSIC) se menciona explícitamente la contaminación lumínica. Habrá diversas modalidades de presentación de trabajos, entre ellas, videos cortos.

Se va a celebrar el V Congreso Internacional Online de Jóvenes Optometristas, SIYO 2020, del 23 al 30 de noviembre de 2020 (Figura 6). El congreso está organizado por un departamento colaborador de SEDOPTICA, el Departamento de Óptica de la Universidad de Valencia, en colaboración con otras entidades y universidades españolas y extranjeras. Se dirige a los profesionales ópticos optometristas en activo y a aquellos que se inician en la labor investigadora y clínica. Contará, además, con la participación de reconocidos científicos del sector.

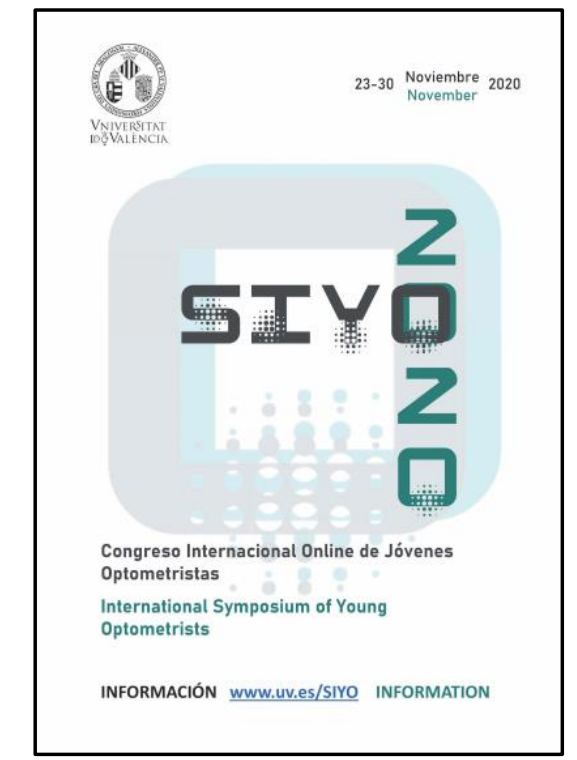

Fig. 6. Póster anunciador del congreso SIYO 2020.

Se ha creado la SPIE@ICFO Chair for Diversity in Photonic Sciences, por iniciativa conjunta del Instituto de Ciencias Fotónicas (ICFO) y la sociedad SPIE. Esta cátedra para la diversidad en las ciencias fotónicas consta de programas y ayudas destinadas al apoyo de estudiantes e investigadores en situaciones desfavorables. Sus objetivos se dirigen primeramente a las mujeres científicas jóvenes de diversos orígenes y, en un contexto más general, pretende ofrecer oportunidades a estudiantes e investigadores con dificultades por su origen o condición. Cabe destacar que es la primera vez que la sociedad SPIE concede a una institución europea un paquete de financiación de esta naturaleza y magnitud, y lo hace a través de la vía del SPIE Endowment Matching program, programa establecido en 2019 para aumentar las posibilidades de docencia e investigación en Óptica y Fotónica a escala internacional.

Las sociedades científicas SPIE y The Optical Society-OSA están colaborando en la adaptación de las actividades de SEDOPTICA así como en el patrocinio de actividades orientadas a la promoción de los jóvenes. El mutuo apoyo entre sociedades afines es, sin duda, uno de los mejores recursos para afrontar entre todos las dificultades que nos plantea la crisis actual. 